\title{
OFICINAS COMO ESTRATÉGIA DE PESQUISA: ARTICULAÇÕES TEÓRICO-METODOLÓGICAS E APLICAÇÔES ÉTICO-POLÍTICAS
}

TALLER COMO ESTRATEGIA DE INVESTIGACIÓN: ARTICULACIONES TEÓRICO-METODOLÓGICAS Y APLICACIONES ÉTICO-POLÍTICAS

USING WORKSHOPS AS A RESEARCH STRATEGY: THEORETICAL AND METHODOLOGICAL ARTICULATIONS AND ETHICAL-POLITICAL

APPLICATIONS

\author{
Mary Jane Spink e Vera Mincoff Menegon \\ Pontificia Universidade Católica de São Paulo, São Paulo /SP, Brasil \\ Benedito Medrado \\ Universidade Federal de Pernambuco, Recife/PE, Brasil
}

\begin{abstract}
RESUMO
Neste artigo discutimos o uso de oficinas como ferramenta metodológica de pesquisa. Partimos do pressuposto que as oficinas são espaços de negociação de sentidos, com potencial crítico de produção coletiva de sentidos. No contexto das oficinas, a negociação de sentidos compreende um processo de interanimação dialógica e de coconstrução interpessoal de identidades, num constante jogo de posicionamentos, que faz fluir a multiplicidade e contraste entre versões sobre o campo-tema que se investiga. Ou seja, o objetivo da oficina não se limita ao registro de informações para fins de pesquisa, uma vez que sensibilizam as pessoas para a temática trabalhada, possibilitando aos seus participantes a negociação de sentidos variados, abrindo espaços para controvérsias e potencializando mudanças. Decorre disso a necessidade de considerar nossa responsabilidade ético-política como pesquisadores que se propõem a abrir espaços de reflexão sobre processos de subjetivação.
\end{abstract}

Palavras-chave: oficinas; metodologia de pesquisa; responsabilidade ético-política; psicologia social.

\section{RESUMEN}

En este artículo discutimos el uso de talleres como herramienta metodológica de investigación. Partimos del presupuesto que los talleres son espacios de negociación de sentidos, con potencial crítico de producción colectiva de sentidos. En el contexto de los talleres, la negociación de sentidos comprende un proceso de inter-animación dialógica y de co-construcción interpersonal de identidades, en un constante juego de posicionamientos, que hace fluir la multiplicidad y contraste entre versiones sobre el campo-tema que se investiga. $\mathrm{O}$ sea, el objetivo del taller no se limita al registro de informaciones para fines de investigación, una vez que sensibilizan a las personas para la temática trabajada, posibilitando a sus participantes la negociación de sentidos variados, abriendo espacios para controversias y potencializando cambios. De eso resulta la necesidad de considerar nuestra responsabilidad ético-política como investigadores que se proponen a abrir espacios de reflexión sobre procesos de subjetivación.

Palabras clave: talleres; metodología de investigación; responsabilidad ético-política; psicología social.

\begin{abstract}
In this article we discuss the use of workshops as a research strategy. The basic assumption is that workshops are spaces for the negotiation of meaning, with potential for the collective production of meanings. The negotiation of meanings, in this context, involves a process of dialogical interanimation and of co-construction of identities in a positioning game that allows for the emergence of multiple and contrasting versions about the theme under discussion. As such, the aim of these workshops is not merely the registration of information for the sake of the research objectives given that it raises awareness about the theme under discussion, allowing space for the emergence of new meanings. Hence the need to take our ethical-political responsibility seriously as researchers committed to the creation of spaces for reflexivity regarding processes of subjectivation.
\end{abstract}

Keywords: workshops; research methods; ethical-political responsibility; social psychology. 


\section{Introdução}

A proposta deste artigo é discutir o uso de oficinas como estratégia de pesquisa. Partimos do pressuposto que as oficinas são espaços com potencial crítico de negociação de sentidos, permitindo a visibilidade de argumentos, posições, mas também deslocamentos, construção e contraste de versões e, portanto, ocasiões privilegiadas para análises sobre produção de jogos de verdade e processos de subjetivação.

As oficinas são usadas em diferentes contextos: na atuação dos movimentos sociais junto a populações variadas (especialmente os mais jovens); em reflexões sobre temas diversos, quando a educação popular tem se mostrado mais oportuna; em programas de prevenção e promoção, na perspectiva da saúde coletiva, desenvolvidos em serviços de saúde, em centros de referência de assistência social, ou em centros comunitários e outros contextos em que se buscam formas participativas de transformação social (Afonso, 2006; Lyra et al., 2002; Paiva, 2000; Silva, 2002).

Esse potencial político se articula a uma riqueza de procedimentos, envolvendo estratégias discursivas diversas, desde expressões artísticas, movimentos corporais e outras formas discursivas, além da própria fala.

No campo da pesquisa em Psicologia Social, apesar da riqueza dessa estratégia de reflexão em grupo, o uso de oficinas nos delineamentos metodológicos é menos familiar. Todavia, estudos que utilizaram oficinas como ferramenta de pesquisa mostram resultados bastante ricos (Curado, 2008; Spink, 2003a, 2003b).

Dentre esses resultados, ressaltamos o potencial das oficinas em promover o exercício ético e político, pois, ao mesmo tempo em que geramos material para análises, criamos um espaço de trocas simbólicas que potencializam a discussão em grupo em relação à temática proposta, gerando conflitos construtivos com vistas ao engajamento político de transformação. $\mathrm{Ou}$ seja, os efeitos da oficina não se limitam ao registro de informações para pesquisa, uma vez que sensibilizam as pessoas para a temática trabalhada, possibilitando aos seus participantes a convivência com a multiplicidade (nem sempre harmônica) de versões e sentidos sobre o tema.

Para fins deste artigo, fundamentamos nossa reflexão sobre a importância do uso de oficinas no contexto de pesquisa, destacando a articulação entre duas dimensões básicas e indissociáveis da construção de conhecimento, a saber: articulações teóricometodológicas e implicações ético-políticas.

$\mathrm{Na}$ construção deste texto, inicialmente posicionamos as oficinas como práticas discursivas que articulam três vetores (foco, plasticidade e política) e se definem como trocas dialógicas que permitem a visibilidade, construção e deslocamento de versões sobre a realidade. Em seguida, apresentamos um exemplo de pesquisa na qual utilizamos oficinas, apresentando detalhes da estrutura, das atividades desenvolvidas, do registro de material discursivo e dos procedimentos utilizados na análise das informações assim geradas (Spink, 2003a, 2003b). Finalmente, abordamos algumas contribuições do uso de oficinas como estratégia de pesquisa no entrecruzamento da dimensão ético-política com as questões teóricas e metodológicas.

Em linhas gerais, na perspectiva aqui defendida, as oficinas são configuradas como ferramentas éticopolíticas privilegiadas, pois propiciam a criação de espaços dialógicos de trocas simbólicas e a coconstrução de outras possibilidades de sentidos acerca das temáticas discutidas, cujos efeitos não se limitam aos usos que os pesquisadores possam fazer desse material, mas também alertam para potenciais transformações nas práticas discursivas geradas naquele contexto, numa fusão inseparável entre o que se convencionou chamar de "coleta de informações e produção de informações".

\section{Oficinas como prática discursiva: foco, plasticidade e política}

A perspectiva a partir da qual compreendemos as oficinas é compartilhada por Emerson Rasera e Marisa Japur (2007) em seu livro Grupo como construção social, no qual apresentam uma leitura construcionista do trabalho de pesquisa e intervenção terapêutica com grupos. Segundo esses autores, o que se produz numa oficina são construções conversacionais dialógicas.

Tomando por base autores como Keneth Gergen, Michael White, David Epston, Tom Andersen e Harlene Anderson e uma vasta e consolidada prática no campo psicoterapia, Rasera e Japur (2007) propõem, em síntese, "redescrições do vocabulário da prática grupal" (p. 199), situando o grupo como um espaço de práticas discursivas. Em outras palavras, compreendem o grupo como um lugar discursivo de negociação, situado no contexto imediato da conversação, no qual se destacam os aspectos relacionais da construção de narrativas de si ou self discursivo. Contudo, destacam esses autores, essa negociação precisa ser compreendida a partir da compreensão de formações 
discursivas institucionalizadas e de construções históricas e culturais mais amplas.

$\mathrm{Na}$ nossa perspectiva, as oficinas são práticas discursivas, ou seja, compreendem maneiras por meio das quais as pessoas produzem sentidos sobre fenômenos a sua volta e se posicionam em relações sociais cotidianas (Spink \& Medrado, 1999). Em outras palavras, são práticas sociais de caráter discursivo cuja produção remete à negociação retórica de versões, apreendida a partir da dimensão performática do uso da linguagem, cujos efeitos são amplos e nem sempre associados a intenções originais.

Do ponto de vista teórico-metodológico, posicionamos a oficina como uma estratégia facilitadora da troca dialógica e da coconstrução de sentidos, cujos procedimentos metodológicos, à primeira vista, parecem articular grupos focais (Ressel et al., 2008), estratégias de dinâmica de grupo (Spink, 2003a) e rodas de conversa (Méllo, Silva, Lima, \& Paolo, 2007).

Da concepção de "grupo focal" herdamos especificamente o caráter do exercício proposto e animado pelo pesquisador: focaliza um tema específico e busca conduzir as produções discursivas do grupo em torno desse tema. Porém, nossa intenção, ao contrário do uso corrente da técnica do grupo focal, não é a de identificar tendências ou consensos, mas ao contrário, focalizamos, em nossas análises, a multiplicidade plástica das práticas discursivas que se produzem no contexto da interação face a face (Spink \& Medrado, 1999). Ou seja, a produção de narrativas particulares e os posicionamentos contrastantes entre interlocutores não devem ser evitados. Nosso foco recai simultaneamente no produto e nas trocas, ou seja, no processo de produção de sentidos que se desenvolve em grupo, resultando em deslocamentos, tensões e contrastes.

Além disso, partimos do pressuposto de que todo grupo produz sua própria dinâmica, e o pesquisador, certamente, não é capaz de apreender plenamente os diversos jogos simbólicos que possam ser gerados no momento da interação em grupo. Ao mesmo tempo, partindo de uma leitura construcionista que entende linguagem como prática social, obviamente, não compreendemos a "dinâmica de grupo" como uma produção psicodinâmica, mas, sobretudo, como trocas dialógicas entre interlocutores que se traduzem em práticas discursivas diversas. Assim, da tradição das "dinâmicas de grupo", resgatamos exclusivamente o caráter criativo das atividades, que buscam articular diferentes estratégias discursivas e enfatizar a plasticidade das interações grupais.
Por último, com a concepção de "rodas de conversa" compartilhamos o caráter político e transformador de uma ação em grupo, compreendendo os encontros grupais como espaços privilegiados para estudar as relações de poder que controlam, selecionam e organizam enunciados, bem como produzem regimes de verdade e formas de resistência.

Esses três vetores (foco, plasticidade e política) definem, em linhas gerais, a dinâmica, o exercício de análise e a finalidade que orientam o uso das oficinas como estratégia metodológica.

\section{Oficinas de risco: exemplificando nossa proposta metodológica}

Para exemplificar nossa proposta metodológica, apresentamos a seguir a estratégia das Oficinas de risco $^{1}$, que começaram a ser desenvolvidas em 1996, no Núcleo de Estudos e Pesquisas em Práticas Discursivas e Produção de Sentidos, do Programa de Pós-graduação em Psicologia Social, da Pontifícia Universidade Católica de São Paulo, no contexto de pesquisas que buscavam entender a relação entre usos da linguagem dos riscos e formas de subjetivação na modernidade tardia (Spink 2003a, 2003b).

Os exemplos utilizados para ilustrar os vários procedimentos das oficinas de risco derivam do relatório da pesquisa Risco e incerteza na sociedade contemporânea: vivendo na sociedade de risco, coordenada por Spink (Projeto Integrado CNPq, Processo 522056/97-0). O objetivo do estudo foi entender como as pessoas definem risco e como isso reflete nas práticas sociais cotidianas. Para tanto, foram realizadas oito oficinas de risco com grupos diversos: praticantes de esportes radicais, homossexuais, mulheres ativistas políticas, estudantes de pós-graduação e usuários(as) de um salão de beleza.

\section{Estrutura da oficina}

Com duração prevista de duas horas, as oficinas contam com a participação de 5 a 12 pessoas. Inicialmente, explicamos aos participantes os objetivos da oficina e da pesquisa, enfatizando a necessidade de gravarmos as discussões, para fins de análise, nos comprometendo a assegurar o anonimato das pessoas que aceitaram o convite para participar da pesquisa. Essas e outras informações estão incluídas no Termo de Consentimento Livre e Esclarecido, assinado antes do início da oficina.

Como o potencial de mobilização da oficina é alto, a condução dos grupos é feita em dupla: um 
coordenador e um observador. Buscamos sempre realizar o grupo em espaços informais, de preferência com os participantes e pesquisadores sentados no chão ou da melhor forma que lhes convier e lhes for possível. $\mathrm{O}$ importante é garantir que os integrantes possam se ver e ter espaço para mobilidade, por exemplo, mudar as classificações das situações de risco, conforme veremos mais adiante. Além disso, são definidos procedimentos para casos de pessoas com dificuldade de escrever, especialmente, a partir do recurso ao desenho de recortes de gravuras em revistas.

No cenário da pesquisa "Risco e incerteza na sociedade contemporânea: vivendo na sociedade de risco", que envolvia populações distintas, decidimos não padronizar a linguagem. Entretanto, para podermos comparar os conteúdos de associações e de situações de risco, padronizamos os procedimentos de registro das informações. Para tanto, treinamos os observadores e coordenadores das oficinas, enfatizando a necessidade de respeitar os limites de cada um, não forçando ninguém a narrar vivências de situações de risco. As narrativas devem ser sempre produções voluntárias, embora esta orientação nem sempre seja exequível, na medida em que o grupo tende a construir suas próprias linhas dialógicas, não suscetíveis a tentativas de diretividade do facilitador.

\section{Atividades e registro de material discursivo}

Como mencionamos anteriormente, as oficinas para fins de pesquisa têm dupla função sensibilização temática e fonte de pesquisa -, que neste caso compreendeu: (a) intervenções visando à sensibilização para os riscos da vida cotidiana e (b) seu uso como instrumento de coleta de material para pesquisa.

As oficinas de risco envolvem quatro etapas: (a) Apresentação; (b) Associação de ideias com a palavra risco (Atividade A); (c) Memórias de situações em que as pessoas se sentiram em risco (Atividade $B$ ) e (d) Os sentidos da prevenção (Atividade C).

Para a primeira etapa, são previstos 15 minutos, dedicados à apresentação do coordenador e do observador, à explicação dos objetivos da atividade (no caso, entender como se pensa risco na vida em geral) e os procedimentos a serem utilizados. Nessa ocasião, também solicitamos permissão para gravar, explicando a dupla função da oficina (pesquisa e sensibilização) e a consequente necessidade de registro. Explicamos, ainda, que a conduta ética em pesquisa com seres humanos requer a explicitação dos objetivos e a assinatura do Termo de Consentimento Livre e Esclarecido. Para assegurar que os participantes entenderam os objetivos e os procedimentos, distribuímos uma cópia para cada um, dando tempo para a leitura individual ou grupal. Finalmente, verificamos se os participantes se conhecem e, se necessário, é feita uma breve apresentação. Para dinamizar essa apresentação, pode-se dividir o grupo em duplas de entrevistadores-entrevistados, que após 10 minutos de conversa passam a uma rodada aberta de apresentações, na qual quem apresenta o colega é seu respectivo entrevistador, estimulando, desde o início, a prática da troca dialógica. Outras estratégias podem ser produzidas, tais como pedir que as pessoas digam um nome e um personagem do cinema com o qual se identificam ou uma cidade que gostariam de conhecer. O importante é que essa atividade, "porta de entrada" da oficina, seja a mais interativa possível, de modo a potencializar trocas no desenvolvimento do encontro.

Considerando a importância do registro das informações, desenvolvemos formulários específicos e padronizamos os passos, conforme sequência abaixo:

1. Registro de informações sobre os participantes (formulário 1).

2. Registro das palavras associadas a risco (atividade A - formulário 2).

3. Recolhimento das tiras e registro das situações de risco (atividades $\mathrm{B}$ e $\mathrm{C}$ ).

4. Gravação das discussões (relativas às atividades B e C).

5. Observações gerais sobre a dinâmica do encontro (funções do observador).

A primeira atividade da oficina consiste na associação de ideias com a palavra risco, com a previsão total de vinte minutos. Distribuímos uma folha de papel e uma caneta para cada integrante, para que escrevam a palavra RISCO. Pedimos, a seguir, para listar todas as palavras e frases que vêm à cabeça quando se fala a palavra risco. Damos dez minutos para essa associação, frisando que podem parar de escrever ao sentir que as palavras e frases não saem mais naturalmente. Vale ressaltar que este primeiro exercício não é suficiente para dar conta da complexidade de modos de definir risco pelo grupo. Ao mesmo tempo, nossa intenção não é a de produzir um glossário para posterior análise semântica, mas antes de tudo gerar um exercício com vistas a mobilizar o grupo para uma dinâmica focal. Nesse exemplo, tomamos "risco" como campo-tema (P. Spink, 2003), mas este foco deve ser adequado à pesquisa que se pretende desenvolver. A seguir, o coordenador escreve todas as associações numa lousa, cartolina ou em flip chart, ou digita em computador com projeção em tela, de modo que os integrantes visualizem as palavras. Enquanto isso, o observador anota as palavras 
no formulário 2. O objetivo dessa atividade é dar visibilidade aos participantes da variedade de termos e expressões usadas para falar sobre o problema em foco (no caso, risco) e, consequentemente, a inexistência de definição única, tendo em vista a polissemia de sentidos associados a essa palavra.

A segunda atividade focaliza as narrativas sobre situações de risco na vida em geral, com a previsão total de 45 minutos para essa etapa. São distribuídas papeletas (tiras de papel medindo cerca de $10 \times 21 \mathrm{~cm}$ ) para cada participante, e solicita-se que pensem em suas vidas, desde quando eram crianças, procurando lembrar-se de situações em que se sentiram em risco. Pedimos, então, para escreverem as situações nas tiras de papel (uma situação para cada papel). Prevemos 15 minutos para as lembranças e seu registro, cujo formato pode ser adaptado a partir das potencialidades e interesses do grupo.

A seguir, solicitamos que classifiquem as situações quanto ao grau de responsabilidade pessoal pela situação vivida, iniciando com aquelas que acham que não tinham nada a ver com o comportamento ou o modo de agir, isto é, que aconteceram por fatores independentes de sua vontade - ou seja, risco na inocência. Essas situações são identificadas com o número 1 e colocadas numa pilha no centro do círculo de participantes.

$\mathrm{Na}$ sequência, pedimos para escreverem o número 2 nas papeletas que narram situações em que, embora sabendo que poderiam envolver risco, não levaram isso em consideração, ou seja, situações que ocorreram sem pensar no risco, colocando-as na segunda pilha, no centro do círculo. Para os demais relatos, que são colocados na última pilha, solicitamos para escreverem o número 3 , pois se referem às situações que envolveram comportamentos em que a pessoa sabia que havia algum risco. Isto é, coisas que fazemos sabendo haver risco - o risco ponderado.

Durante a discussão que ocorre após as classificações, lembramos que é possível reclassificar as situações a qualquer momento da discussão. Seguese uma discussão sobre as situações, começando com os riscos na inocência, solicitando-se voluntários para falar de uma ou mais situações que escreveram nas papeletas. Nesse momento, o gravador é acionado. No final do exercício, as papeletas são recolhidas para futuras análises. A diferenciação entre formas distintas de vivência de risco é uma estratégia para abrir diálogos sobre medidas preventivas em saúde e sobre a imponderabilidade de alguns riscos. Outras estratégias de diferenciação podem ser empregadas, tendo em vista o objetivo da pesquisa em curso. Se o objeto de pesquisa for, por exemplo, a homofobia, essa diferenciação poderia ser gerada a partir da organização das narrativas entre relações interpessoais e expressões institucionais de preconceito ou entre situações em que os participantes eram praticantes ou eram alvo da discriminação. Ou seja, o objetivo dessa diferenciação (que pode ser feita na forma de agrupamentos de papeletas por número, cores ou qualquer outra forma) é fomentar posicionamentos e tensões sobre aspectos diretamente associados ao problema-foco em questão.

A terceira atividade volta-se mais especificamente à prevenção dos riscos, sendo previsto um total de 45 minutos para essa etapa. Quatro perguntas orientaram a discussão: (a) Que tipo de riscos vale a pena correr; (b) Que tipo de riscos vale a pena prevenir; (c) Que tipos de comportamentos preventivos são adotados no cotidiano de cada participante e (d) Pensando nas situações de vida em que se sentira em risco, o que seria prevenção. Essas perguntas foram formuladas pensando nos objetivos da pesquisa sobre riscos. Obviamente, para uso em outras pesquisas, devem ser substituídas tendo em vista seus objetivos específicos.

A oficina é encerrada, solicitando uma breve avaliação do grupo sobre as atividades e sua dinâmica. Nesse momento, curiosamente, surgem enunciados que contribuem sobremaneira no processo de análise das práticas discursivas produzidas em grupo sobre o problema investigado.

\section{Procedimentos de análise das oficinas}

A análise de cada oficina compreende vários procedimentos. Em primeiro lugar, descrevemos o contexto de realização da oficina, incluindo aspectos que antecederam seu desenvolvimento (divulgação, convite, receptividade), a caracterização da oficina (local, data, duração, assinatura dos consentimentos livres e esclarecidos, características de cada participante e dinâmica da discussão) e, para finalizar, o registro de possíveis eventos após a oficina (como eventuais contatos com os pesquisadores). Esses registros se aproximam menos de uma "descrição" neutra de estruturas móveis e eventos que caracterizaram o encontro e mais uma "inscrição" situada e posicionada do pesquisador.

Incluem também inscrições de elementos humanos e não-humanos (Tirado \& Domènech, 2005), tais como sala, clima, organização, decoração, localização da unidade na comunidade e assim por diante, entendendo que esses elementos também constituem as práticas discursivas. Desse modo, tanto narrativas produzidas pelos entrevistados como as produzidas pelo/a pesquisador/a constituem objetos de nossas análises. 
Para auxiliar a transcrição é feito um registro gráfico da disposição dos participantes no decorrer das atividades, conforme exemplo abaixo. O coordenador é identificado com $\mathbf{C}$, o observador/a com $\mathbf{O}$ e os participantes com $\mathbf{P}$.

Figura 1. Distribuição espacial dos participantes no grupo CEAG2

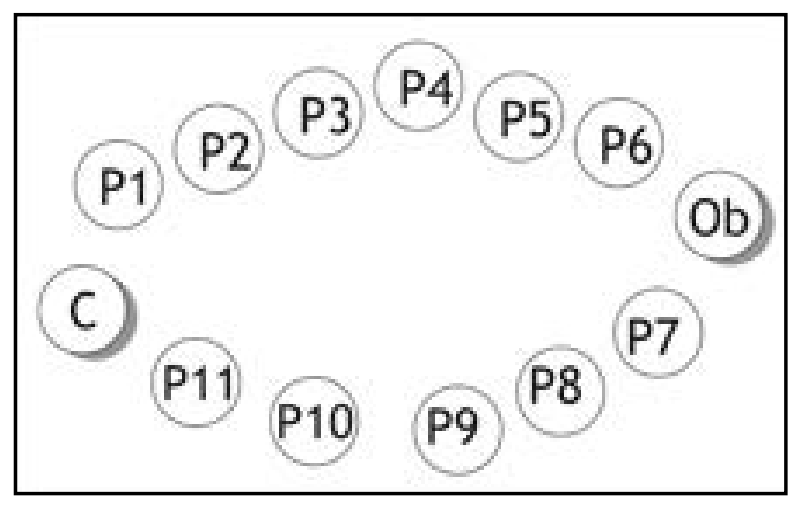

O segundo passo da análise centra-se no material obtido nas associações com a palavra risco (Atividade
A), que são transcritas para o formulário, possibilitando: (a) verificar a diversidade de associações; (b) analisar as diferenças de produção entre os membros do grupo e (c) transferir as associações e frequência com que apareceram no grupo para uma tabela síntese, visando à comparação entre os diferentes grupos quando o desenho de pesquisa incluir diversos grupos. A ilustração abaixo exemplifica esse exercício a partir das associações produzidas em uma oficina realizada com integrantes da Associação de Mães de Adolescentes em Situação de Risco (AMAR).

Como terceiro passo de análise, as narrativas de risco registradas nas papeletas (Atividade B) são transcritas para o formulário desenvolvido de forma a registrar as situações de risco segundo as classificações apresentadas e discutidas na realização da oficina, a saber: risco na inocência; risco não pensado; risco deliberado. As situações são registradas para cada oficina (conforme exemplo abaixo) e, posteriormente, são reorganizadas em forma de síntese, para possibilitar a comparação entre os diferentes grupos que participaram das oficinas.

Além dos registros escritos nas papeletas, a segunda atividade gera, como material de análise,

Quadro 1. Associações com a palavra risco - Oficina AMAR (25/08/2000)

\begin{tabular}{|l|c|c|c|c|c|}
\hline \multirow{2}{*}{ ASSOCIAÇÕES À PALAVRA RISCO } & \multicolumn{3}{c|}{ PARTICIPANTES } \\
\hline & $\mathbf{1}$ & $\mathbf{2}$ & $\mathbf{3}$ & $\mathbf{4}$ & $\mathbf{5}$ \\
\hline 1. Faca & $\mathrm{X}$ & & & $\mathrm{X}$ & \\
\hline 2. Tesoura & $\mathrm{X}$ & & & & \\
\hline 3. Revolver & $\mathrm{X}$ & & & & \\
\hline 4. Sair à rua de noite & $\mathrm{X}$ & & & & \\
\hline 5. Passar em lugares ermos & $\mathrm{X}$ & & & & \\
\hline 6. Denunciar a Febem & $\mathrm{X}$ & & & & \\
\hline 7. Perigo de vida e de morte todo o tempo & & $\mathrm{X}$ & & & \\
\hline 8. Em todo momento nós e nossos filhos corremos riscos & & $\mathrm{X}$ & & & \\
\hline 9. Drogas & & & $\mathrm{X}$ & & \\
\hline 10. Violência & & & $\mathrm{X}$ & & \\
\hline 11. Borboleta & & & & $\mathrm{X}$ & \\
\hline 12. Mandruvá (lagarta) & & & & $\mathrm{X}$ & \\
\hline 13. Fogo & & & & $\mathrm{X}$ & \\
\hline 14. Febem & & & & $\mathrm{X}$ & \\
\hline 15. Fome & & & & $\mathrm{X}$ & \\
\hline 16. Raiva & & & & $\mathrm{X}$ & \\
\hline 17. Medo & & & & $\mathrm{X}$ & \\
\hline 18. Álcool & & & & $\mathrm{X}$ & \\
\hline 19. Perigo & & & & & $\mathrm{X}$ \\
\hline 20. Angústia pelos meninos da Febem & & & & & $\mathrm{X}$ \\
\hline 21. Risco de cair & & & & & $\mathrm{X}$ \\
\hline 22. Risco de ser roubada (minha vida) & & & & $\mathrm{X}$ \\
\hline
\end{tabular}


Quadro 2: Situações de risco arroladas na oficina com homossexuais profissionais de um salão de cabeleireiros $(23 / 08 / 2000)$

\begin{tabular}{|c|c|c|c|}
\hline SITUAÇÕES DE RISCO & $\begin{array}{l}\text { Risco } \\
\text { imprevisível }\end{array}$ & $\begin{array}{l}\text { Sem pensar } \\
\text { no risco }\end{array}$ & $\begin{array}{l}\text { Sabendo do } \\
\text { risco }\end{array}$ \\
\hline $\begin{array}{l}\text { 1. Um grupo de colegas de escola numa festa junina, pulando } \\
\text { fogueira. }\end{array}$ & $\mathrm{X}$ & & \\
\hline 2. Me apaixonei por outra pessoa. & $\mathrm{X}$ & & \\
\hline 3. Quando tive internado por causa de uma hepatite. & $\mathrm{X}$ & & \\
\hline 4. Falecimento do meu pai aos dez anos. & $\mathrm{X}$ & & \\
\hline 5. Quando fico sozinho e me sinto deprimido. & $\mathrm{X}$ & & \\
\hline 6. Eu e mais amigos brincando em alto mar de caiaque. & & $\mathrm{X}$ & \\
\hline 7. Cacau morreu por causa de um michê. & & $\mathrm{X}$ & \\
\hline 8. Briguei no trânsito e quase tomei um tiro. & & $\mathrm{X}$ & \\
\hline $\begin{array}{l}\text { 9. Quando meu amigo ficou internado na U.T.I. por um acidente de } \\
\text { carro [provocado por ingestão de bebida alcoólica]. }\end{array}$ & & $\mathrm{X}$ & \\
\hline 10. Uma vez que saí com garoto de programa. & & & $\mathrm{X}$ \\
\hline 11. Experimentei cocaína aos 37 anos. & & & $\mathrm{X}$ \\
\hline 12. Já transei sem camisinha. & & & $\mathrm{X}$ \\
\hline 13. Levei um estranho para meu apartamento & & & $\mathrm{X}$ \\
\hline 14. Mudança de estado para S.P. & & & $\mathrm{X}$ \\
\hline 15. Arrisquei meu dinheiro em jogo. & & & $\mathrm{X}$ \\
\hline 16. Quando eu transei, pela primeira vez sem camisinha. & & & $\mathrm{X}$ \\
\hline 17. Pensando em voltar a morar em Porto Alegre. & & & $\mathrm{X}$ \\
\hline 18. Fazer um trabalho mau feito. Ex.: tinturas. & & & $\mathrm{X}$ \\
\hline 19. Mandei meu namorado embora. & & & $\mathrm{X}$ \\
\hline $\begin{array}{l}\text { 20. Um grupo de amigos vestidos de drag queen, voltando de uma } \\
\text { festa. }\end{array}$ & & & $\mathrm{X}$ \\
\hline
\end{tabular}

as discussões que foram gravadas e transcritas. A estratégia de sistematização dessas discussões em grupo segue os parâmetros do material gerado na terceira atividade, que comentamos a seguir tendo em perspectiva o estudo sobre risco. Como dito anteriormente, as questões que orientam essa etapa do encontro devem ser produzidas a partir dos objetivos de cada pesquisa em particular, considerando os interesses do pesquisador, mas também conhecimentos prévios identificados na revisão da literatura que possam visibilizar versões ou argumentos em contraste ou tensão.

No caso da pesquisa sobre risco, a terceira atividade consiste em discussões específicas sobre prevenção de riscos.

As gravações das discussões realizadas nas atividades dois e três são transcritas de duas maneiras: (a) transcrição sequencial para propiciar uma visão de conjunto das temáticas abordadas, dos processos de negociação de sentidos dos riscos e da dinâmica da discussão em grupo;

(b) transcrição integral.

A transcrição sequencial é feita escutando-se a gravação (antes da transcrição integral). Anota-se a sequência das falas, fazendo-se uma breve descrição da temática. Tem por objetivo dar uma visão de conjunto - dinâmica e conteúdo. Busca-se, portanto, fazer anotações que não ultrapassem uma linha por participante, conforme exemplifica o próximo quadro.

A transcrição sequencial possibilita a seleção de trechos da discussão onde há processos de negociação 


\section{Quadro 3. Transcrição sequencial relativa às linhas 193-230 da transcrição integral} (Oficina AMAR)

C. Pede mais situações do Grupo 2, e ninguém mais fala. Passa então ao grupo 3, do risco corrido com consciência de sua existência.

P4. Conta do aborto que fez, mesmo sabendo das consequências que isso poderia trazer.

C. Pergunta se mais alguém que comentar.

P1. Medo que sentia de perder a virgindade na juventude. Corria riscos em determinados locais, e ia mesmo assim.

C. Comenta que esse foi um risco bom.

P5. Fala que correu risco mesmo quando namorou um vizinho casado, aos 14 anos.

P1. Atribui a isso o fato de sua filha fazer o que faz ((risos)).

C. Pergunta como foi o risco nessa situação.

P5. Risco da vizinha descobrir. Foi um risco bom, principalmente por ter sido amante e não esposa. Se tivesse continuado com ele, estaria bem pois ele ficou rico.

C. Pergunta se seria então um risco de ter mais dinheiro nesse caso.

P5. Disse que sim, mas que por outro lado talvez não estivesse mais viva.

C. Pede mais situações vividas sabendo do risco.

P3. Relata a experiência de engravidar aos 15 anos, mesmo com medo da mãe saber corria o risco e engravidou.

C. Pergunta se alguém mais se recorda de risco corridos que valeram a pena.

P1. Conta que todos que valeram forma com namorados, como namorar 3 rapazes ao mesmo tempo. Tinha o risco de um descobrir do outro, e da mãe descobrir.

P2. Fala sobre namoro com dois rapazes ao mesmo tempo e corria o risco de um descobrir a respeito do outro.

de sentidos sobre risco (ou outro problema pesquisado) em temáticas variadas. Esses trechos são analisados com a técnica dos mapas dialógicos (Spink \& Lima, 1999). Para a construção desses mapas, no exemplo da pesquisa sobre riscos na vida cotidiana, utilizamos três colunas: descrição da situação de risco; explicações e justificativas a ela relacionadas e emoções associadas, transferindo para as colunas a transcrição integral do trecho selecionado na transcrição sequencial. Obviamente, as colunas do mapa são definidas a partir dos objetivos específicos de pesquisa e da identificação de temas na fase da transcrição sequencial.

O Quadro 4 mostra o segmento de mapa que resultou do trecho da transcrição sequencial utilizado como ilustração no quadro anterior.

No exemplo desta pesquisa sobre risco, em particular, com a análise das narrativas produzidas pelos entrevistados, aprofundamos a compreensão sobre os sentidos dos riscos na sociedade contemporânea, de modo a auxiliar no desenvolvimento de atividades preventivas em diferentes contextos. Foi possível, ainda, em termos teóricos, aprofundar a compreensão sobre a pluralidade dos sentidos de risco, propondo três tradições discursivas (risco como perigo, risco como probabilidade, risco aventura), que foram formatadas no tempo longo das linguagens utilizadas para falar de risco (Menegon \& Spink, 2007; Spink, Seiji, \& Alves, 2005).

Em linhas gerais, é importante ressaltar que, nesta proposta metodológica, o exercício apresentado ao grupo se caracteriza pelo estímulo à visualização de diferentes versões sobre o problema investigado. Isso se dá inicialmente a partir da técnica de associação de palavras que dá visibilidade à polissemia de termos e expressões e, mais adiante, nas narrativas que apresentam formas diversas de apropriação e atualizações particulares dessas formas diversas de significação. Contudo, o que se destaca nesta 
Quadro 4: Risco nas relações amorosas - Mapa da oficina AMAR (25/08/2000)

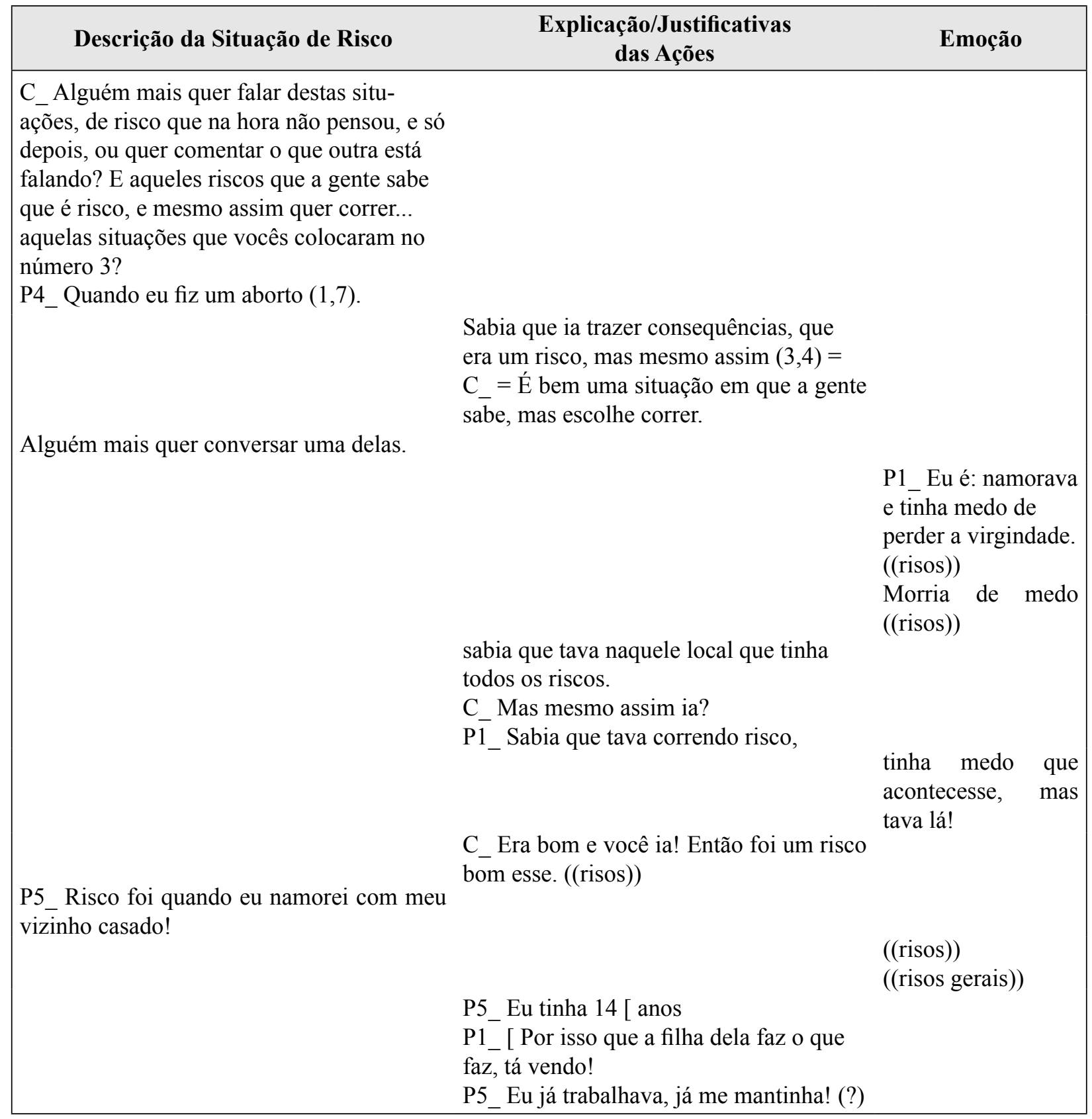

proposta é o incentivo ao exercício reflexivo que se inaugura com a atividade de agrupar as narrativas (em papeletas), a qual provoca deslocamentos de sentidos e potencializa discussões em grupo, visualizando tensões e controvérsias. Esse movimento é ampliado na última atividade, em que são apresentadas questões que visam a desestabilizar e contrastar possibilidades.

Assim, ao invés de priorizar consensos ou aspectos que se afirmam como centrais, a partir da repetição, os procedimentos de análise (transcrição sequencial e mapas dialógicos) visam a dar visibilidade às dinâmicas que se estabelecem entre os interlocutores, em produtivas disputas promovidas pela oficina.

\section{Considerações finais}

Espaços em que se promove a visibilidade e negociação de versões têm implicações teóricas, metodológicas e éticas, uma vez que tendem a produzir efeitos de transformação simbólica que ultrapassam o momento de realização das discussões, assim como extrapolam os usos analíticos que porventura 
sejam feitos pelos pesquisadores. Os ecos de nossas pesquisas continuam vibrando tempos depois da realização daquilo que se convencionou chamar de "coleta de dados".

Em termos teóricos, esses espaços abrem uma janela privilegiada para aproximações ao "tempo longo" da circulação de repertórios histórica e culturalmente produzidos.

É nesse tempo histórico que podemos apreender os repertórios disponíveis que serão moldados pelas contingências sociais de época, constituindo as vozes de outrora que povoam nossos enunciados. Não os temos mais como teorias, pois muitas já perderam sua razão de ser; também não os temos como acontecimento, tempo da vida cotidiana, da interanimação, das ilusões. Só os temos como fragmentos e, por isso mesmo, como repertórios. (Spink \& Medrado, 1999, p. 51)

A possibilidade de deixar fluir a diversidade de repertórios nos possibilita entender os interstícios dos processos de produção de sentidos. Vale apontar que, nas postulações de Potter e colaboradores (por exemplo, Potter \& Wetherell, 1987), os repertórios são as unidades de construção das práticas discursivas - o conjunto de termos, descrições, lugares-comuns e figuras de linguagem - que demarcam o rol de possibilidades de construções discursivas, tendo por parâmetros o contexto em que essas práticas são produzidas e os estilos específicos, que Mikhail Bakhtin denomina de gêneros de discurso (Bakhtin, 2003).

A aproximação com esses repertórios marca, também, o tempo curto das interações, definido por Spink e Medrado (1999) como o tempo da interanimação dialógica_que nos possibilita entender a dinâmica da produção de sentidos.

Nesse tempo, estão em pauta, concomitantemente, a possibilidade da compreensão (understanding), da comunicação e a construção discursiva das pessoas ... Nesse momento específico, as possibilidades de combinação das vozes, ativadas pela memória cultural de tempo longo ou pela memória afetiva de tempo vivido, fazem-se presentes. (Spink \& Medrado, 1999, p. 53)

No contexto das oficinas, a negociação de sentidos compreende um processo de interanimação dialógica e de coconstrução interpessoal de identidades, num constante jogo de posicionamentos (Davies \& Harré, 1990), que faz fluir a multiplicidade de versões sobre o tema em discussão, atravessadas por "jogos de verdade". Somos quem somos porque o outro que nos interpela acata ou disputa nossa versão de self.
Mais uma razão, portanto, para levar a sério nossa responsabilidade ético-política como pesquisadores que se propõem a abrir espaços de reflexão sobre processos de subjetivação.

Em termos metodológicos, as implicações para os pesquisadores ocorrem quando se defrontam com as vicissitudes dos processos de construção do conhecimento, acatando alguns horrores metodológicos (Woolgar, 1988) como a presença incômoda da indexicalidade, o imperativo da reflexividade e o reconhecimento da inconclusividade na produção de conhecimento advinda de nossas pesquisas. De maneira resumida, apoiando-nos em Spink e Menegon (1999, pp. 86-88), reflexividade refere-se "à espiral da interpretação e aos efeitos da presença do pesquisador nos resultados da pesquisa", a indexicalidade diz respeito "à situacionalidade, ou vinculação com o contexto: o sentido muda à medida que a situação muda" e a inconclusividade, por sua vez, refere-se "à aceitação plena da processualidade dos fenômenos sociais".

Por fim, em termos éticos, compreendemos pesquisa como uma prática social, marcada por dinâmicas ético-políticas. Portanto, não podemos ignorar que, ao promover um encontro marcado pelo incentivo à visibilização da diversidade, assim como a explicitação de possíveis tensões e conflitos, favorecemos diálogos pautados pela retórica, portanto, pela produção de jogos de verdade.

O que produzimos em uma oficina escapa à mente isolada de um indivíduo ou à produção singular de um falante. São produtos da interação, portanto, parciais, situados e móveis. Constituem práticas discursivas que tomam corpo no coletivo, inauguradas a partir do convite feito pelo pesquisador e enredadas, posteriormente, nas diferentes formas de inscrição que esse pesquisador possa produzir, orientadas no processo de análise, por suas questões de pesquisa e pela literatura sobre a qual sustenta seus argumentos.

Além disso, sendo uma produção dialógica, as oficinas, certamente, podem gerar produções discursivas que não têm necessariamente compromisso com experiências prévias ou com formulações conceituais mais amplas das pessoas. Consistem em produções situadas, cujas análises não podem se pretender generalizáveis ou representativas do que uma comunidade discursiva pensa a respeito.

Assim, sendo a oficina um encontro que favorece a negociação (nem sempre consensual) de versões sobre o mundo e sobre nós próprios, ela se configura, antes de tudo, como jogos de linguagem, de base retórica, orientados pelo poder, ou seja, em "jogos 
de verdade", que situam, caracterizam e inscrevem processos de subjetivação.

O conceito de "jogos de verdade", como bem descreve Birman (2002), foi desenvolvido por Foucault a partir do conceito de "jogos de linguagem" proposto por Wittgenstein (1999), na obra Investigações Filosóficas. Porém, segundo Birman, essa mudança não se configurou apenas como substituição de termos, por sinonímia. Essa mudança marca um importante deslocamento que visa a trazer para primeiro plano de análise a dimensão do poder (nexo crucial para a constituição dos jogos de verdade) nas relações que produzem/ legitimam/ regulam verdades e modos de ser nas sociedades. Ou seja, para Foucault, a verdade não preexiste à linguagem ou ao sujeito; ela se inscreve em relações entre as pessoas, mediadas por jogos de poder, e como efeito produz práticas de si, regulando possibilidades. Nesse sentido, Foucault nos questiona:

Em quais jogos de verdade, o homem tem condições de pensar seu próprio ser, quando se percebe como louco, doente, ou como ser vivo, falante e laborioso? E como criminoso? E através de que jogos de verdade ele deve se reconhecer como homem de desejo? (Foucault, 1984, p. 13)

Portanto, em sua obra, Foucault se preocupa menos em definir o que é verdade, se ela existe, se é uma ficção, intangível ou absoluta. Sua preocupação recai, sobretudo, no questionamento sobre os processos de legitimação de "regimes de verdade" e os efeitos desses regimes sobre processos de subjetivação, ou seja, "a verdade se legitimaria e se inscreveria nos corpos dos indivíduos pela mediação de processos de subjetivação" (Birman, 2002, p. 307).

Uma definição de "jogos de verdade" muito útil aos propósitos deste texto é apresentada por Carolina Massena e Rosane Castro (2012):

Jogos de verdade são o conjunto de regras de produção de verdade, o conjunto de procedimentos que conduzem a um determinado resultado, que pode ser considerado - em função de seus princípios e de suas regras de procedimento - como válido ou não. ... É também lugar de enfrentamento social e debate político, encarado sob a forma de "lutas ideológicas", cada lado defendendo seu ponto de vista sem se interrogarem sobre como cada discurso, lado do debate. (p. 1)

A partir dessa definição e das contribuições de Birman, entendemos que a análise das práticas discursivas que se produzem numa oficina deva incidir nesses jogos "pela leitura crítica e insistente de suas modalidades de formação, de cristalização e de enraizamento nas individualidades, para que possa enunciar outros jogos de verdade" (Birman, 2002, p. 308).

\section{Nota}

Originalmente, a nomeação usada pelo grupo de pesquisa era "oficina sobre risco". Porém, considerando, do ponto construcionista, a indissociabilidade entre a prática e linguagem, optamos pela preposição "de", como uma estratégia para enfatizar que o que produzimos numa oficina não é uma narrativa sobre eventos passados (no caso, experiências de risco), mas, de algum modo, fabricamos discursivamente um risco, na medida em que os jogos que se desenrolam neste encontro coletivo certamente moldam as condições de possibilidades e produzem um certo "riscolinguagem".

\section{Referências}

Afonso, M. L. M. (Org.). (2006). Oficinas em dinâmica de grupo na área da saúde. São Paulo: Casa do Psicólogo.

Bakhtin, M. (2003). Os gêneros do discurso. In P. Bezerra (Org.), Estética da criação verbal (pp. 261-306). São Paulo: Martins Fontes. (Original publicado em 1979)

Birman, J. (2002). Jogando com a verdade. Uma leitura de Foucault. Physis, 12(2), 301-324.

Curado, J. (2008). Gênero e os sentidos do trabalho social. Campo Grande, MS: UCDB.

Davies, B. \& Harré, R. (1990). Positioning: The discursive production of selves. Journal for the Theory of Social Behaviour, 20(1), 43-63.

Foucault. M. (1984). História da Sexualidade II. O Uso dos Prazeres. Rio de Janeiro: Graal.

Lyra, J., Medrado, B., Nascimento, P., Galindo, D., Moraes, M., \& Pedrosa, C. (2002). "A gente não pode fazer nada, só podemos decidir sabor de sorvete". Adolescentes: de sujeito de necessidades a um sujeito de direitos. Cadernos CEDES, 22(1), 9-21.

Massena, C. \& Castro, R. (2012). Verdade/Jogos de Verdade. Acesso em 19 de julho, 2012, em http://www.ufrgs.br/epsico/subjetivacao/espaco/jogos-de-verdade.html

Méllo, R. P., Silva, A. A., Lima, M. L. C., \& Paolo, A. F. Di. (2007). Construcionismo, práticas discursivas e possibilidades de pesquisa em psicologia social. Psicologia \& Sociedade, 19(1), 26-32.

Menegon, V. S. M. \& Spink, M. J. (2007). Novas tecnologias reprodutivas conceptivas: problematizando a comunicação sobre riscos. In V. Ferreira, A. M. Ávila, \& A. P. Portella (Orgs.), Feminismo e novas tecnologias reprodutivas (pp. 13-22). Recife: SOS CORPO, Instituto Feminista para a Democracia.

Paiva, V. S. F. (2000). Fazendo arte com camisinha sexualidades jovens em tempos de Aids. São Paulo: Summus.

Potter, J. \& Wetherell, M. (1987). Discourse and social psychology: Beyond attitudes and behaviour. London: Sage Publications.

Rasera, E. F. \& Japur, M. (2007). Grupo como construção social. São Paulo: Vetor.

Silva, R. C. (2002). Metodologias participativas para trabalhos de promoção de saúde e cidadania. São Paulo: Vetor. 
Ressel, L. B. et al. (2008). O uso do grupo focal em pesquisa qualitativa. Texto \& contexto Enfermagem, 17(4), 779-786.

Spink, M. J. P. (2003a). Ao sabor dos riscos: reflexões sobre a dialogia e a co-construção de sentidos. In M. J. P. Spink, Psicologia social e saúde: práticas, saberes e sentidos (pp. 295-324). Petrópolis, RJ: Vozes.

Spink, M. J. P. (2003b). Risco e incerteza na sociedade contemporânea: vivendo na sociedade de risco (Relatório de pesquisa). São Paulo: Conselho Nacional de Desenvolvimento Científico e Tecnológico.

Spink, M. J. P. \& Lima, H. (1999). Rigor e visibilidade: a explicitação dos passos da interpretação. In M. J. P. Spink (Org.), Práticas discursivas e produção de sentidos no cotidiano: aproximações teóricas e metodológicas (pp. 93122). São Paulo: Cortez.

Spink, M. J. P. \& Medrado, B. (1999). Produção de sentidos no cotidiano: uma abordagem teórico-metodológica para análise das práticas discursivas. In M. J. P. Spink (Org.), Práticas discursivas e produção de sentidos no cotidiano: aproximações teóricas e metodológicas (pp. 41-61). São Paulo: Cortez.

Spink, M. J. P. \& Menegon, V. S. M. (1999). A pesquisa como prática discursiva: superando os horrores metodológicos. In M. J. P. Spink (Org.), Práticas discursivas e produção de sentidos no cotidiano: aproximações teóricas $e$ metodológicas (pp. 63-92). São Paulo: Cortez.

Spink, M. J. P., Seiji, S., \& Alves, M. P. (2005). Da exacerbação dos sentidos no encontro com a natureza: contrastando esportes radicais e turismo de aventura. Psicologia, Reflexão e Crítica, 18(1), 26-38.

Spink, P. (2003). Pesquisa de campo em Psicologia Social: uma perspectiva pós-construcionista. Psicologia \& Sociedade, 15(2), 18-42.

Tirado, F. \& Domènech, M. (2005, novembro/dezembro). Asociaciones heterogéneas y actantes: el giro postsocial de la teoría del actor-red. AIBR. Revista de Antropología Iberoamericana. Acesso em 13 de março, 2013, em http:// www.redalyc.org/articulo.oa? id $=62309905$

Wittgenstein, L. (1999). Investigações Filosóficas (J. C. Bruni, Trad., Coleção Os Pensadores). São Paulo: Editora Nova Cultural.

Woolgar, S. (1988). Science: The very idea. Chichester, UK: Ellis Horwood; London: Tavistock.

\section{Agradecimento}

Ao CNPq pelo apoio e financiamento.

Recebido em: $24 / 10 / 2011$

Revisão em: 07/04/2012

Aceite em: 07/10/2012

Mary Jane Spink é Professora Titular na Pontifícia Universidade Católica de São Paulo, Coordenadora do Núcleo de Estudos sobre Práticas Discursivas e Produção de Sentidos (PUC-SP), bolsista de Produtividade em Pesquisa do CNPq, Nível 1A. Endereço: PPG Psicologia Social-PUCSP. Rua Monte Alegre, 984. Perdizes. São Paulo/SP, Brasil. E-mail: mjspink@pucsp.br

Vera Mincoff Menegon é Doutora em Psicologia Social pela PUC-SP, pesquisadora do Núcleo de Estudos sobre Práticas Discursivas e Produção de Sentidos (PUC-SP). Tem como foco de pesquisa o uso de tecnologias no campo da saúde reprodutiva, com ênfase nos processos de produção de sentidos, estratégias de governo e políticas públicas. E-mail: mincoff@uol.com.br

Benedito Medrado é Doutor em Psicologia Social pela PUC/SP; docente dos cursos de Graduação e Programa de Pós-graduação em Psicologia da Universidade Federal de Pernambuco. É um dos fundadores do Instituto

Papai e coordena o Núcleo de Pesquisas em Gênero e Masculinidade (Gema/UFPE, cadastrado no CNPq desde 1998); presidente da Abrapso (Gestão 2010-2011). Bolsista de Produtividade em Pesquisa do CNPq. E-mail: beneditomedrado@gmail.com

\section{Como citar:}

Spink, M. J., Menegon, V. M., \& Medrado, B. (2014). Oficinas como estratégia de pesquisa: articulações teórico-metodológicas e aplicações ético-políticas. Psicologia \& Sociedade, 26(1), 32-43. 